Tema: Gestão Sistêmica

\title{
MELHORIAS NOS ENTREPOSTOS VISANDO APRIMORAR O PROCESSO DE EXPEDIÇÃO*
}

\author{
Jaine Ana Ferreira \\ Cristine Gonzales de Almeida ${ }^{2}$ \\ Luiz Gonzaga da Silva ${ }^{3}$ \\ Ricardo Vaz da Silva
}

\section{Resumo}

A GAL tem uma constante preocupação em desempenhar as atividades de embarque e faturamento de forma eficiente e ao mesmo tempo receber a produção cada vez melhor. Pensando nisso, a equipe buscou parâmetros que pudessem medir a eficiência do Entreposto13 e propor melhorias, visando eliminar as constantes paradas de equipamentos por falta de área de armazenagem no Entreposto. O desejo era reduzir a quantidade de bobinas removidas no momento do carregamento, pois quando se reduz esse o manuseio interno, reduz-se o tempo do embarque e consequentemente agiliza o recebimento de bobinas no entreposto. Várias outras melhorias de infraestruturas e gestão de pessoas e equipamentos foram necessárias para que o objetivo final fosse alcançado. Objetivo esse que se resume em reduzir paradas dos equipamentos de Preparação de Bobinas à Quente para aumentar a velocidade de embarque.

Palavras-chaves: Eficiência do EE13; Gestão integrada; Otimização de equipamentos e mão de obra.

\section{IMPROVEMENTS IN WAREHOUSES TO IMPROVE THE PROCESS AND EXPEDITION}

\section{Abstract}

The GAL is a constant concern perform activities of shipment and billing form efficient and at the same time receive the best production ever. Thinking about it, we sought a parameter that could measure the efficiency of Warehouse 13, whose production delivery suffered with constant stops for lack of equipment storage area. The desire was to reduce the amount of coils removed at the time of loading. When this reduces handling internal speeds up boarding and consequently receiving coils in the warehouse. However, only do not solve the measurement. However, only do not solve the measurement problem. Hence, various other improvements of infrastructure and management of people and equipment were needed for the final objective was reached. Goal that this boils down to reduce downtime of equipment Preparation of Hot Rolled Coils and speed of shipment.

Keywords: Efficiency EE13; Integrated management; Optimization of equipment and manpower.

1 Eletromecânica/Matemática, Coordenadora de Escoamento, Gerência de Entrepostos e Escoamento (GAL), Companhia Siderúrgica Nacional, Volta Redonda, Rio de Janeiro, Brasil.

2 Segurança do Trabalho, Supervisora de Escoamento, Gerência de Entrepostos e Escoamento (GAL), Companhia Siderúrgica Nacional, Volta Redonda, Rio de Janeiro, Brasil.

3 Matemático, Técnico de Desenvolvimento, Gerência de Entrepostos e Escoamento (GAL), Companhia Siderúrgica Nacional, Volta Redonda, Rio de Janeiro, Brasil.

4 Segurança do Trabalho, Técnico de Desenvolvimento, Gerência de Entrepostos e Escoamento (GAL), Companhia Siderúrgica Nacional, Volta Redonda, Rio de Janeiro, Brasil.

\footnotetext{
* Contribuição técnica ao 69 Congresso Anual da ABM - Internacional e ao 14ํㅡㄹ ENEMET - Encontro Nacional de Estudantes de Engenharia Metalúrgica, de Materiais e de Minas, 21 a 25 de julho de 2014, São Paulo, SP, Brasil.
} 


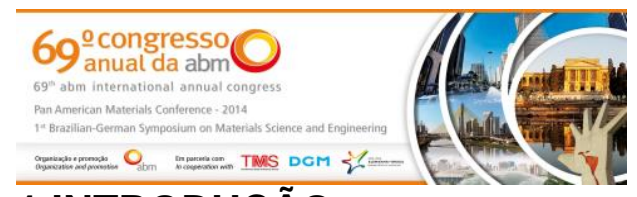

\section{INTRODUÇÃO}

A GAL tem uma constante preocupação em receber a produção cada vez melhor, evitando ser um gargalo logístico, e por isso está sempre buscando melhorias nos seus métodos, equipamentos e entrepostos, visando se adequar de forma rápida às evoluções do setor Produtivo.

Dentre outros objetivos, manter a eficiência do EE\#13 com o mínimo de $60 \%$, tornando o Entreposto mais ágil e garantindo área para recebimento dos produtos oriundos das Linhas de Preparação de Bobinas Quentes II e III.

Este, sem dúvida, era o nosso o maior desafio, pois, devido a questões de segurança e produtividade, precisávamos de uma solução rápida e com os recursos que tínhamos em mãos.

Nossa primeira atitude foi ouvir o pessoal do piso e interagir com aqueles que futuramente iriam colocar em prática qualquer ideia que pudesse surgir. Isso nos possibilitou identificar oportunidades de aperfeiçoarmos a nossa gestão de pessoas e equipamentos, o que resultou no alcance dos objetivos traçados.

A satisfação em derrubar desafios foi tamanha que hoje podemos observar que a motivação para novas melhorias vem crescendo constantemente em toda a equipe.

\section{MATERIAIS E MÉTODOS}

\subsection{Relocação de 02 Viradores de Bobinas para Entrepostos Distintos}

As bobinas laminadas a quentes são entregues pela produção no eixo vertical. Hoje, $90 \%$ dos clientes da Companhia que compram esse produto, exigem o recebimento no eixo horizontal.



Figura 1.

A gerência possui 08 viradores de bobinas, distribuídos em 04 pontos, sendo 05 viradores em um só galpão de grande capacidade, porém esse galpão tornava-se 0 gargalo no escoamento das linhas de produção e no embarque.Com a relocação dos viradores, aumentamos os pontos de recebimento e inversão dos materiais, agilizando o escoamento das linhas de produção e o embarque de produtos.

\footnotetext{
* Contribuição técnica ao 69 Congresso Anual da ABM - Internacional e ao 14ํㅡㄹ ENEMET - Encontro Nacional de Estudantes de Engenharia Metalúrgica, de Materiais e de Minas, 21 a 25 de julho de 2014, São Paulo, SP, Brasil.
} 


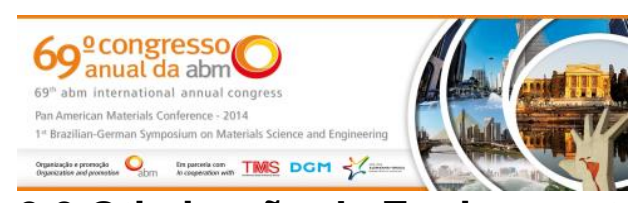

\subsection{Otimização de Equipamentos e Pessoal entre as Supervisões}

Durante nossa atividade de ouvir os colaboradores do piso, pudemos observar que, mesmo pertencendo ao mesmo setor, muitos não sabiam das dificuldades, processos e metas dos outros. Foi quando o grupo decidiu elaborar um rodízio de posto de trabalho, para que todos pudessem se interar do processo da gerencia como um todo.

Iniciamos com substituição de férias em postos de trabalhos diferentes. Depois passamos a substituir um profissional pelo outro da mesma categoria, até que pelo menos $80 \%$ do grupo tivesse no mínimo uma visão macro da gerência a qual pertencia.

Após o grupo obter essa visão, notamos que o interesse em saber se o outro está precisando de ajuda, já estava ocorrendo sem necessidade de intervenção da supervisão.

Muitas ideias para facilitar as atividades corriqueiras foram surgindo e colocadas em prática, com o intuito de aumentarmos a disponibilidade de mão de obra, facilitando a otimização de pessoas e equipamentos, tais como:

- Instalação de escada móvel para acesso a caminhões e espelho parabólico para facilitar a visibilidade de manobras ferroviárias;

- Retirada de coluna na baia de carregamento rodoviário para maior segurança e rapidez nas manobras de veículos e consequentemente rapidez no embarque de produtos;

- Confecção de peneira para coleta de resíduo de varrição. Atendimento ao programa de Coleta Seletiva.

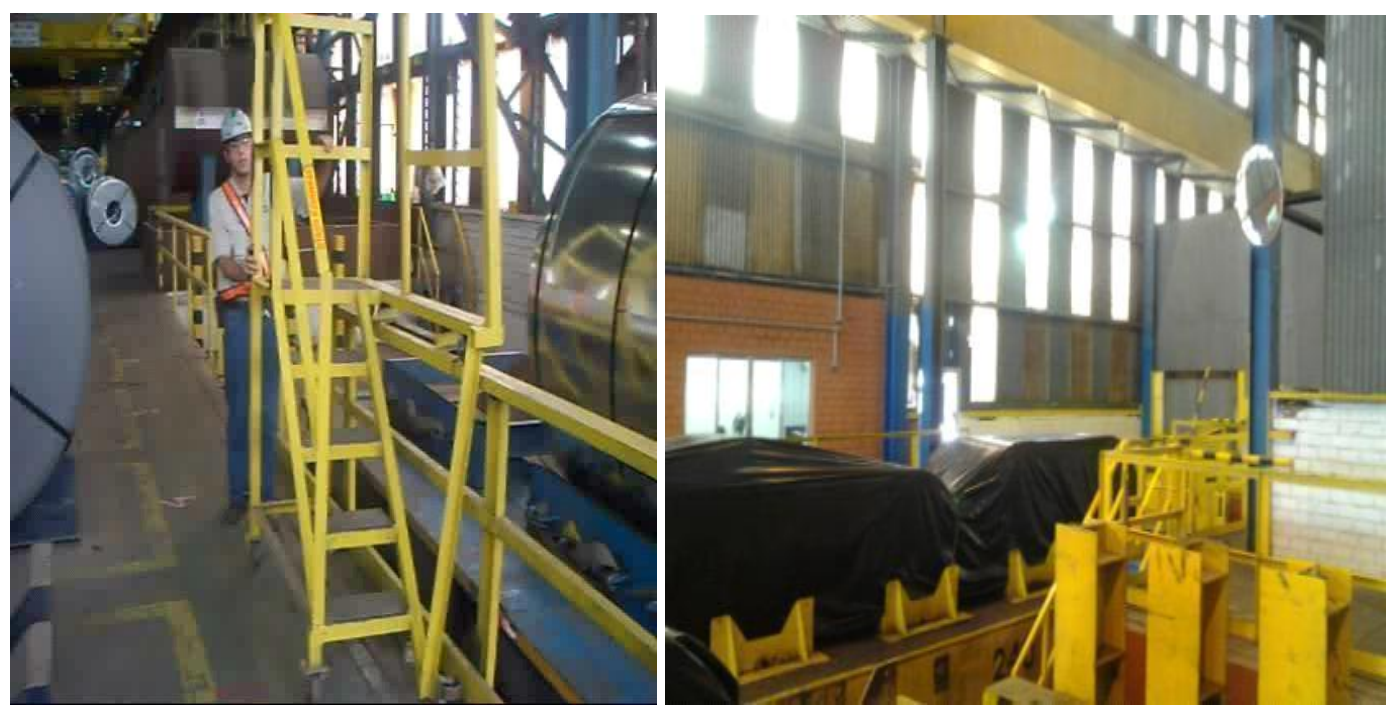

Figura 2. Instalação de escada móvel para acesso a caminhões e espelho parabólico para facilitar a visibilidade de manobras ferroviárias

\footnotetext{
* Contribuição técnica ao 69 Congresso Anual da ABM - Internacional e ao 14ํㅡㄹ ENEMET - Encontro Nacional de Estudantes de Engenharia Metalúrgica, de Materiais e de Minas, 21 a 25 de julho de 2014, São Paulo, SP, Brasil.
} 

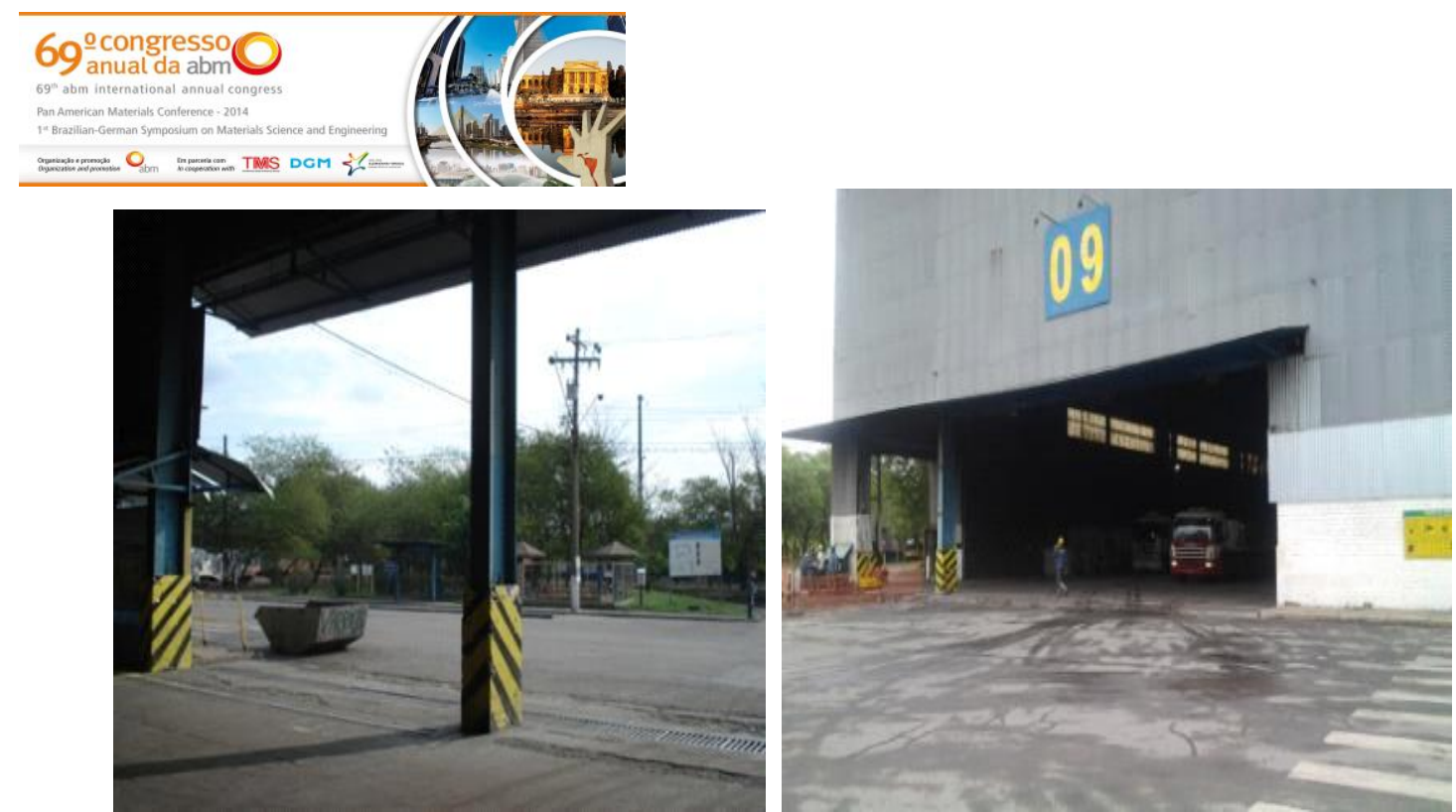

Figura 3. Retirada de coluna na baia de carregamento rodoviário para maior segurança e rapidez nas manobras de veículos e consequentemente rapidez no embarque de produtos.

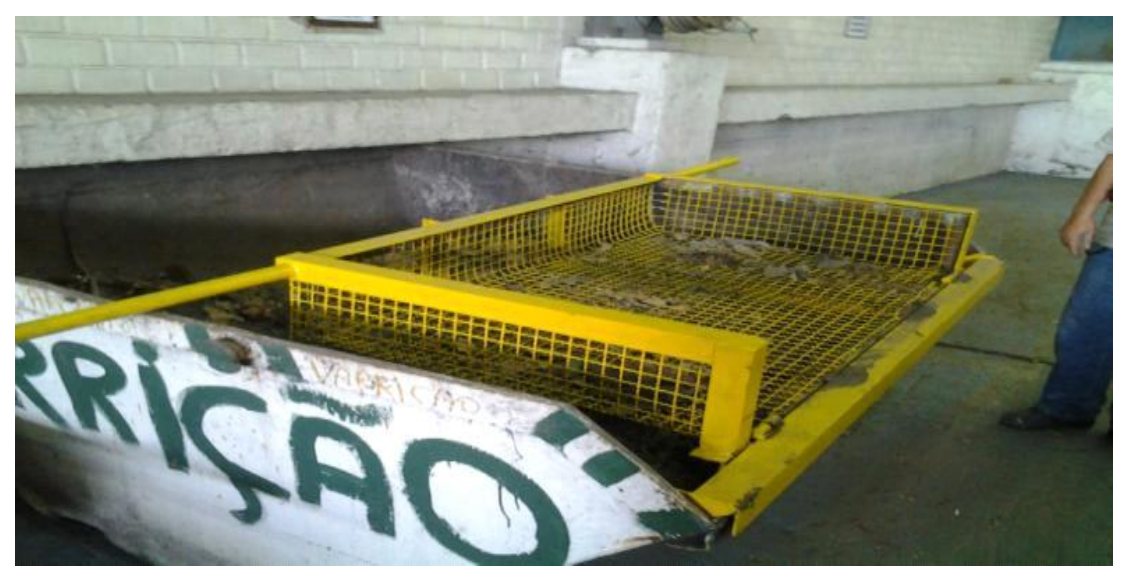

Figura 4. Confecção de peneira para coleta de resíduo de varrição. Atendimento ao programa de Coleta Seletiva.

Com tudo isso, conhecimentos foram compartilhados, talentos foram descobertos, a colaboração entre os empregados aumentou e nosso trabalho fluiu como esperado.

\section{RESULTADOS}

A média de eficiência (relação entre quantidade de bobinas embarcadas e quantidade de bobinas removidas) do entreposto que recebe esse tipo de produto em 2013 foi além do estipulado que é de $60 \%$.

\footnotetext{
* Contribuição técnica ao $69^{\circ}$ Congresso Anual da ABM - Internacional e ao 14ํㅡㄹ ENEMET - Encontro Nacional de Estudantes de Engenharia Metalúrgica, de Materiais e de Minas, 21 a 25 de julho de 2014, São Paulo, SP, Brasil.
} 




Figura 5.

Reduzimos as paradas por falta de área de armazenagem nas linhas de preparação de bobinas quente para zero em 2013

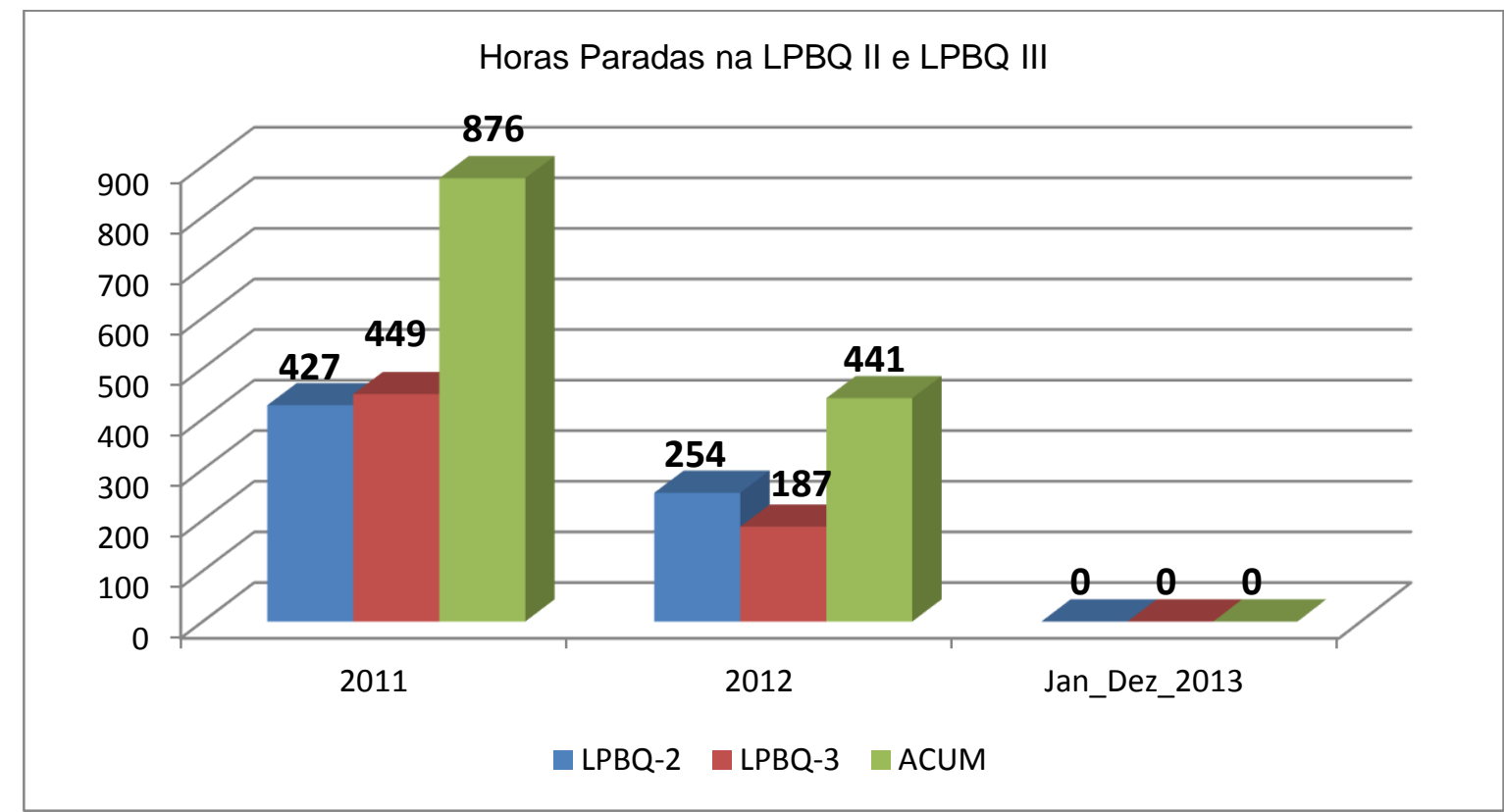

Figura 6.

Desde setembro de 2012, estamos conseguindo manter a área livre para o recebimento dos produtos das Linhas de Preparação de Bobinas Quente.

\footnotetext{
* Contribuição técnica ao $69^{\circ}$ Congresso Anual da ABM - Internacional e ao 14ํㅡㄹ ENEMET - Encontro Nacional de Estudantes de Engenharia Metalúrgica, de Materiais e de Minas, 21 a 25 de julho de 2014, São Paulo, SP, Brasil.
} 

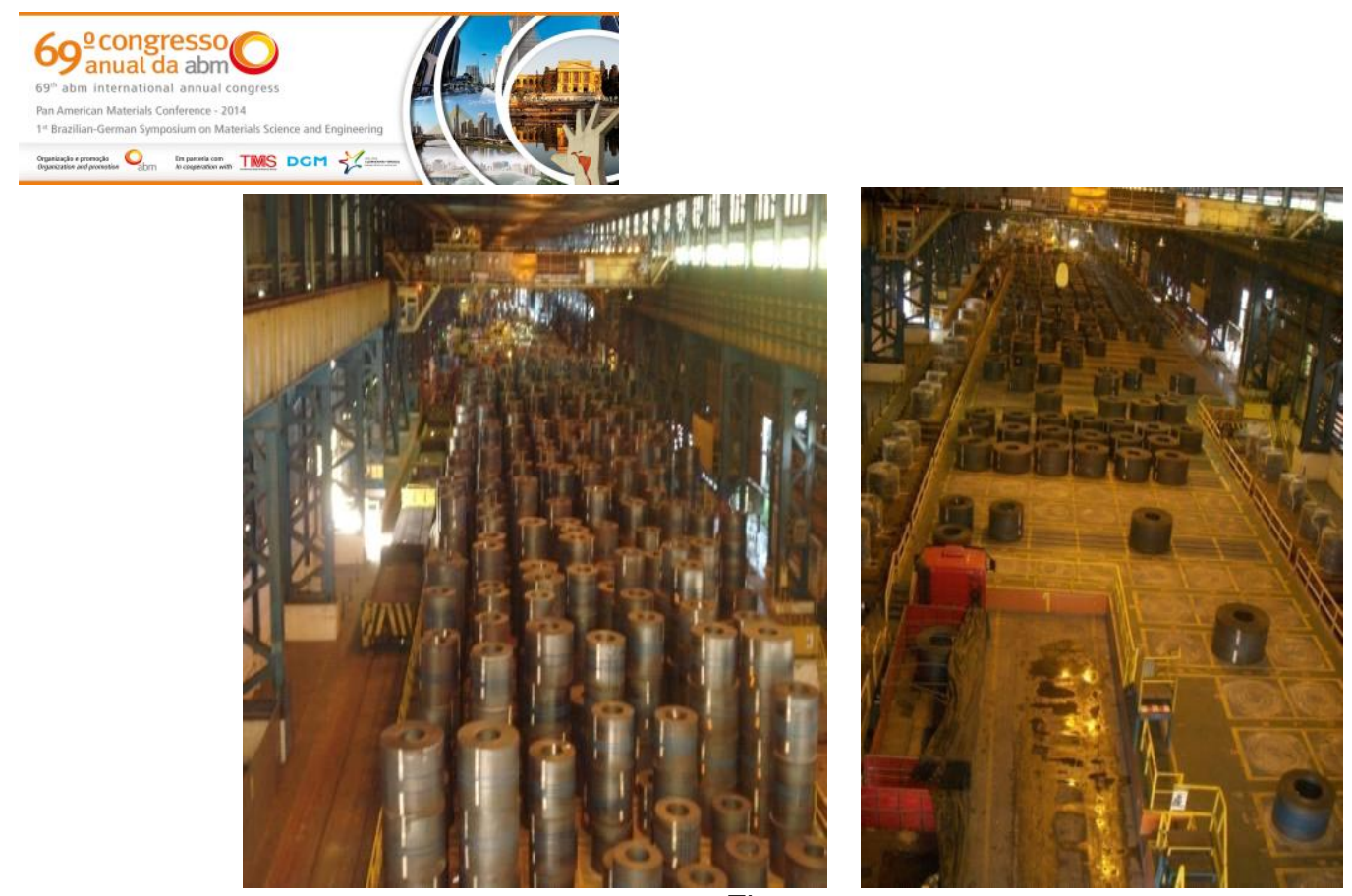

Figura 7

E o mais importante, eliminação de Risco de Acidentes como o ocorrido em 17/08/2012, onde 47 bobinas foram derrubadas, ocasionando perda de processo e retrabalho.

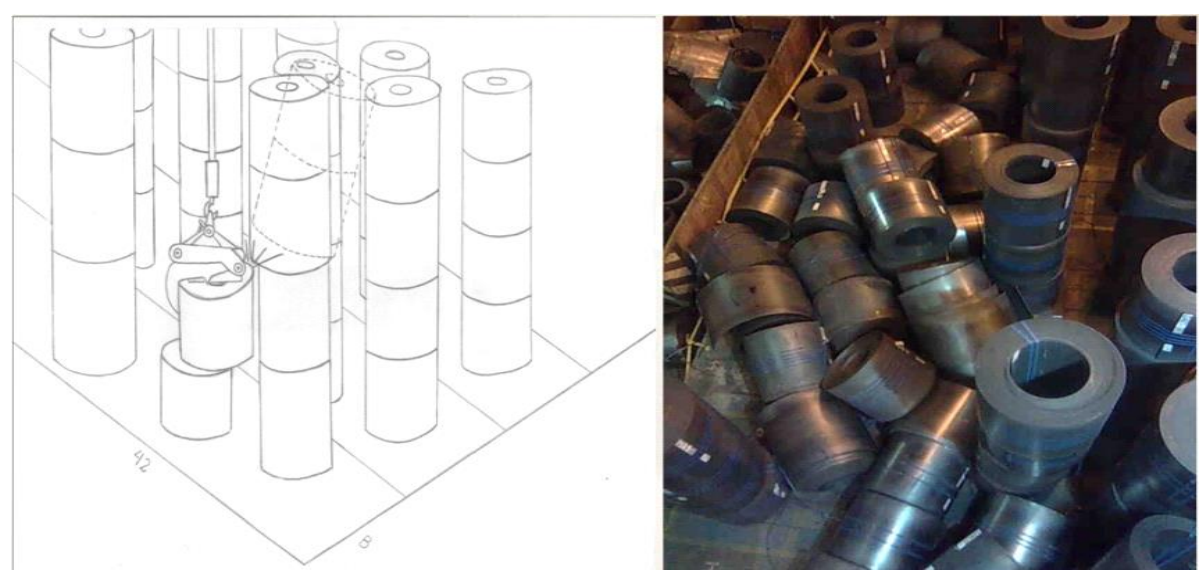

Figura 8.

\section{CONCLUSÃo}

Uma gestão integrada para administrar recursos (equipamento e mão de obra) possibilitando a criação de sinergias de forma mais abrangente e otimizada, pode ser o melhor caminho para a garantia de alcance de metas.

\section{Agradecimentos}

Gerente: Otaviano Pinto de Oliveira; Engenheiro de Desenvolvimento: Carlos Augusto Viana Leal; e Mecânico/Soldador/Maçariqueiro: Rogério Aparecido Costa.

\section{BIBLIOGRAFIA}

Albert Einstein. No meio de qualquer dificuldade encontra-se a oportunidade.

\footnotetext{
* Contribuição técnica ao $69^{\circ}$ Congresso Anual da ABM - Internacional e ao 14ํㅡㄹ ENEMET - Encontro Nacional de Estudantes de Engenharia Metalúrgica, de Materiais e de Minas, 21 a 25 de julho de 2014, São Paulo, SP, Brasil.
} 